\title{
Improved synthesis of carbon nanotubes with junctions and of single-walled carbon nanotubes
}

\author{
F L DEEPAK, ${ }^{1}$ A GOVINDARAJ ${ }^{1,2}$ and C N R RAO ${ }^{1,2, *}$ \\ ${ }^{1}$ Chemistry and Physics of Materials Unit and DST Unit on Nanosciences, Jawaharlal Nehru Centre for \\ Advanced Scientific Research, Jakkur PO, Bangalore 560064 \\ ${ }^{2}$ Solid State and Structural Chemistry Unit, Indian Institute of Science, Bangalore 560012 \\ e-mail: cnrrao@jncasr.ac.in
}

\begin{abstract}
Pyrolysis of thiophene over nickel nanoparticles dispersed on silica is shown to yield Yjunction carbon nanotubes with smaller diameters than those obtained by the pyrolysis of organometallicthiophene mixtures. In the presence of water vapour, the pyrolysis of organometallic-hydrocarbon mixtures yields single-walled nanotubes, as well as relatively narrow-diameter carbon nanotubes with Y-junctions. Pyrolysis of organometallic-hydrocarbon mixtures, in the absence of water vapour, only gives nanotubes with T- and Y-junctions.
\end{abstract}

Keywords. Carbon nanotubes; T- \& Y-junctions of nanotubes; single-walled carbon nanotubes.

\section{Introduction}

Novel methods of synthesis and purification of multiwalled (MWNTs) and single-walled carbon nanotubes (SWNTs) have attracted a great deal of attention. ${ }^{1}$ Although evaporation of graphite under electrical discharge has been employed widely for the preparation of carbon nanotubes, decomposition of hydrocarbons over metal nanoparticles in a reducing atmosphere is found to be very effective for preparing MWNTs. In this context, the one-step synthesis of MWNTs by the pyrolysis of organometallic precursors is noteworthy. ${ }^{2}$ Specially interesting is the discovery that the pyrolysis of organometallics in the presence of thiophene gives rise to $\mathrm{Y}$-junction nanotubes. ${ }^{3}$ In this method, the organometallic produces metal particles in-situ, around which the nanotubes form, the metal particles transforming to the sulphide. ${ }^{4}$ By this means, Y-junction nanotubes with an outer diameter of $\sim 100 \mathrm{~nm}$ or more are obtained. We considered it important to prepare Y-junction MWNTs with narrower diameters for possible applications. For this purpose, we have carried out the pyrolysis of thiophene over $\mathrm{Ni}$ catalysts supported on silica and we report the results of this study.

In addition to the synthesis of Y-junction MWNTs with relatively small diameters, we were interested

Dedicated to Prof J Gopalakrishnan on his 62nd birthday

*For correspondence in examining the role of water vapour in preparing junction nanotubes as well as SWNTs. In this connection, it is to be noted that high quality carbon nanotubes have been obtained from graphite by water-assisted synthesis. ${ }^{5}$ An efficient water-assisted synthesis of impurity-free SWNTs has been reported by Hata et $a l .^{6}$ A low-temperature growth of SWNTs by water plasma chemical vapour deposition (CVD) has also been reported recently. ${ }^{7}$ We have investigated the effect of water vapour on the nature of the carbon nanotubes obtained by the pyrolysis of organometallic precursors. For this purpose, we have examined the nanotubes obtained by the pyrolysis of ferrocene in mixtures with ethylene or acetylene bubbled through thiophene in a stream of moist $\mathrm{H}_{2}$. For purposes of comparison, we have also carried out the pyrolysis of ferrocene-hydrocarbon mixtures in the absence of water vapour. In the presence of water vapour, we obtain MWNTs with junctions at the inlet of the furnace and SWNTs in the outlet region. In the absence of water vapour, we obtain MWNTs with T- and Y-junctions.

\section{Experimental}

Pyrolysis of thiophene was carried out over a nickel catalyst prepared by the following procedure. About $1.2 \mathrm{~g}$ of nickel acetate (corresponding to $0.005 \mathrm{~mol}$ ) was dissolved in $5 \mathrm{ml}$ of acidified ethanol, followed by the addition of $2 \mathrm{ml}$ of tetraethyl orthosilicate (TEOS) and stirring for 5 minutes. To this homoge- 


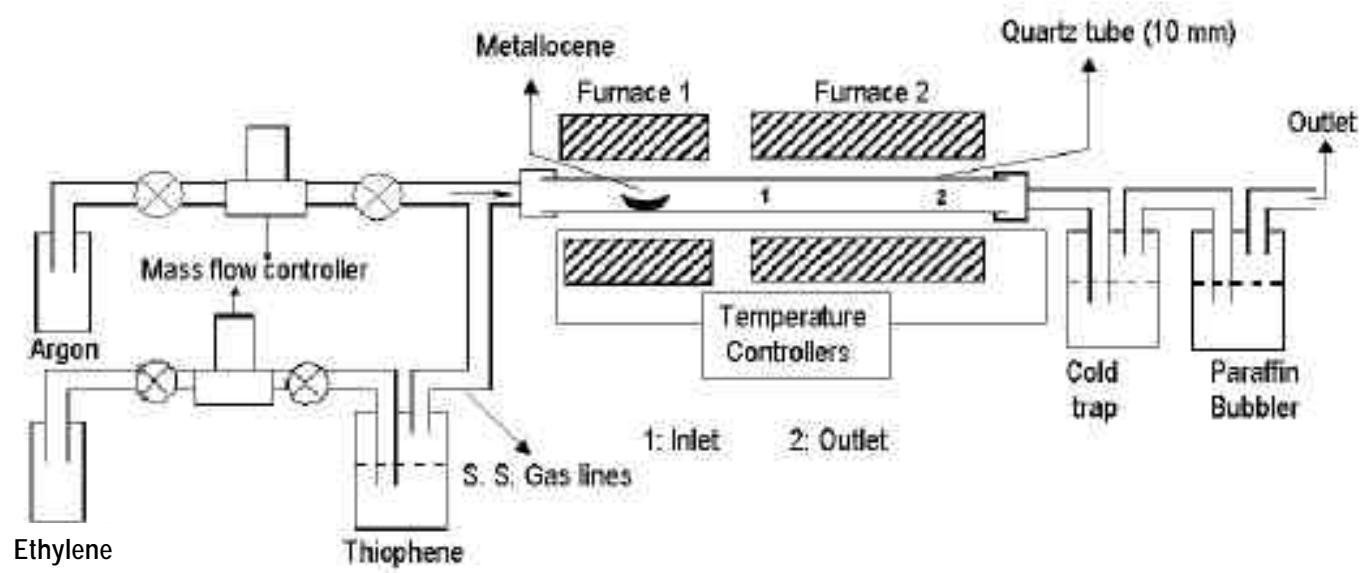

Figure 1. Pyrolysis setup for the synthesis of carbon nanotube Y-junctions employing metallocene and thiophene.
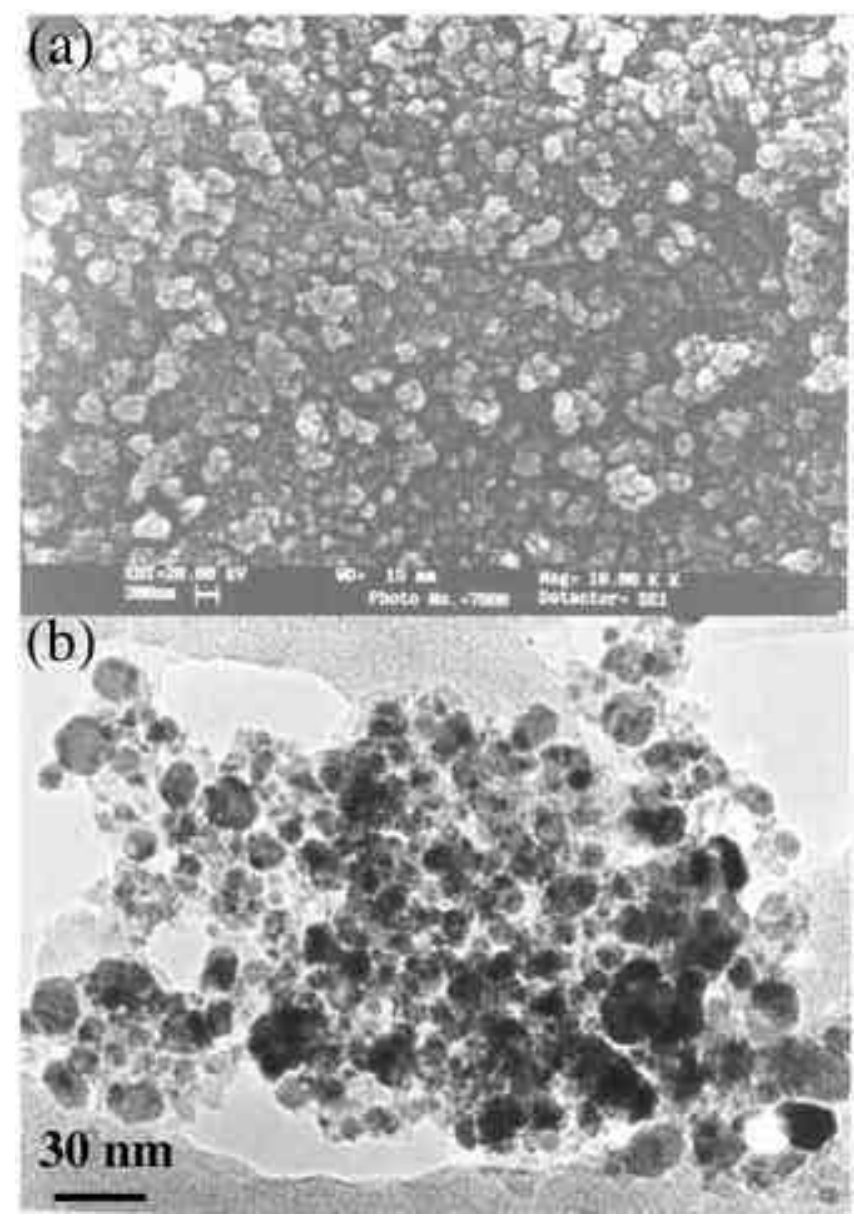

Figure 2. (a) SEM and (b) TEM images of the Ni/silica catalyst.

neous solution, $1.5 \mathrm{ml}$ of $\mathrm{HF}$ (38\%) was added dropwise and the resultant mixture stirred at $50^{\circ} \mathrm{C}$ till it resulted in the formation of a gel. The gel was dried in an oven at $75^{\circ} \mathrm{C}$ for $24 \mathrm{~h}$, calcined at $400^{\circ} \mathrm{C}$ for $2 \mathrm{~h}$ and reduced in $\mathrm{H}_{2}$ atmosphere for $2 \mathrm{~h}$. The temperature was subsequently raised to $1000^{\circ} \mathrm{C}$ and thiophene vapours were passed over the catalyst for $20 \mathrm{~min}$, by bubbling $\mathrm{H}_{2}(50 \mathrm{sccm}$, sccm = standard cubic centimetre per minute) through thiophene. The sample collected from the boat was examined by transmission electron microscopy.

In order to study the effect of water vapour on nanotubes obtained by the pyrolysis of thiophene and organometallic mixtures, we have employed two procedures. In both the procedures, a known quantity of ferrocene was sublimed in one furnace and was carried by the flow of Ar gas (2000 sccm) to a second furnace. In figure 1 , we show the experimental set-up that was employed during the course of these reactions. In procedure (i), three streams of gases were carried to the second furnace where pyrolysis occurred. Ethylene or acetylene $(10 \mathrm{sccm})$ bubbled through thiophene, was carried to the pyrolysis zone in the second furnace by the second stream, while the third stream was that of $\mathrm{H}_{2}(20 \mathrm{sccm})$ which bubbled through water. Pyrolysing these mixtures in the second furnace at $1000^{\circ} \mathrm{C}$ yielded nanotubes in the inlet and outlet regions. We have compared the results of procedure (i) with the results from the pyrolysis carried out by procedure (ii) in the absence of water vapour.

Scanning electron microscope (SEM) images were recorded with a Leica $\mathrm{S}-440$ i electron microscope. The nanotubes were examined with a JEOL JEM3010 transmission electron microscope (TEM) operating at $300 \mathrm{kV}$. 


\section{Results and discussion}

In figures $2 \mathrm{a}$ and $\mathrm{b}$, we show the SEM and TEM images of the silica-supported nickel catalyst. We see that
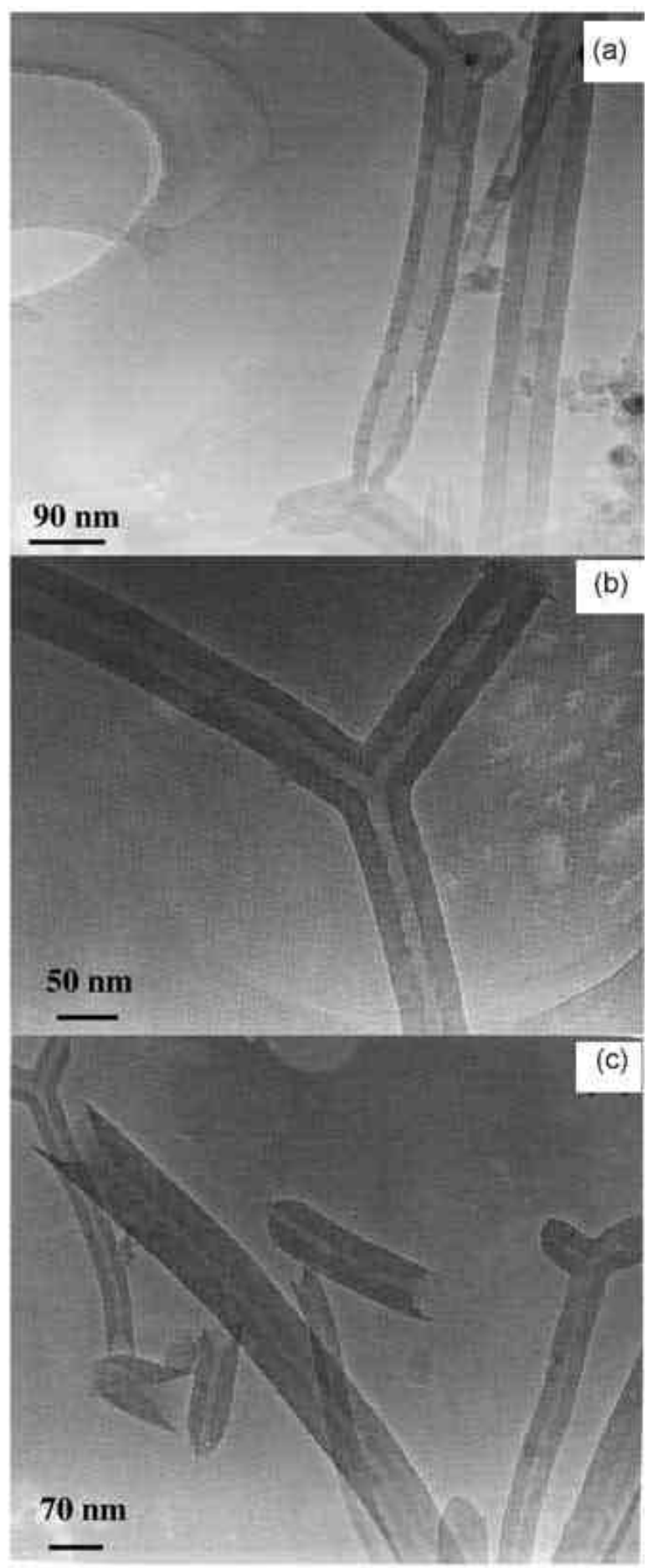

Figure 3. TEM images of $\mathrm{Y}$-junction nanotubes obtained by the pyrolysis of thiophene over a $\mathrm{Ni} / \mathrm{SiO}_{2}$ catalyst. The junction in (a) shows the presence of multiple junctions on a single nanotube.

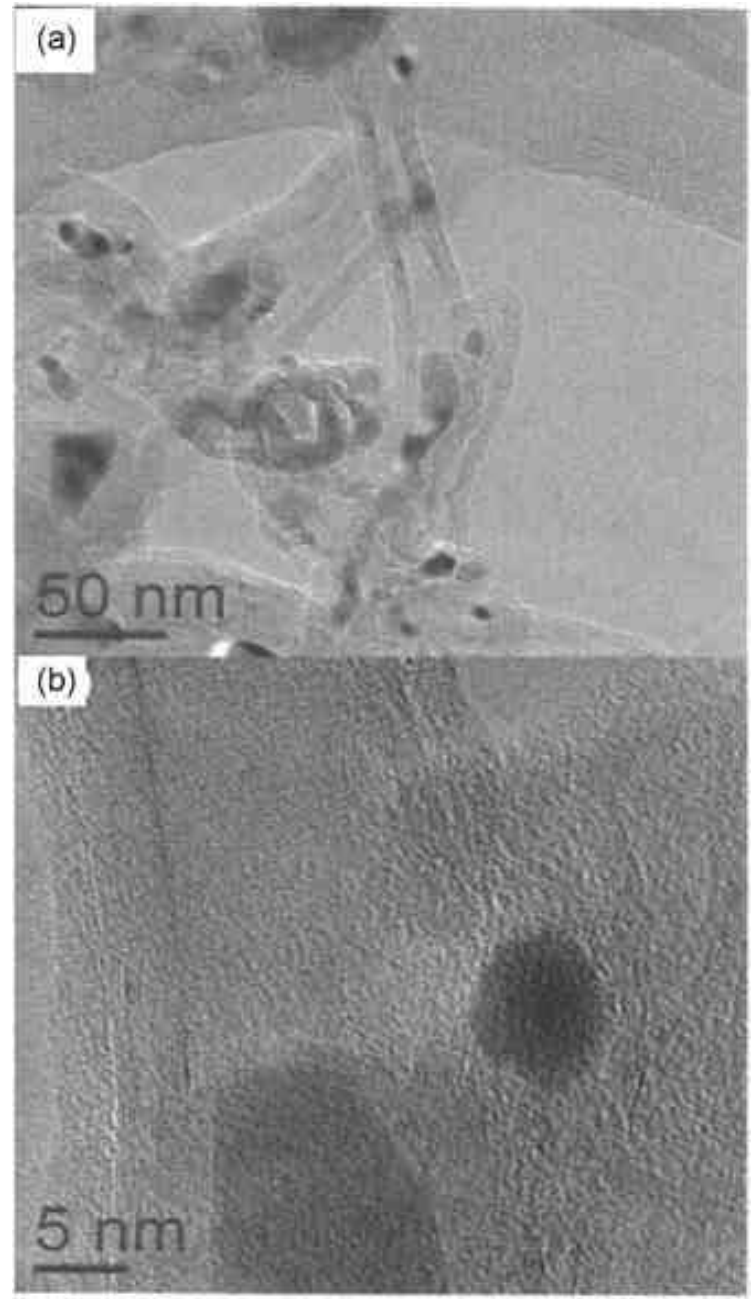

Figure 4. (a) and (b) TEM and HREM image of Yjunction nanotube found in the inlet regions obtained by the pyrolysis of ferrocene-water-ethylene-thiophene mixtures (procedure i).

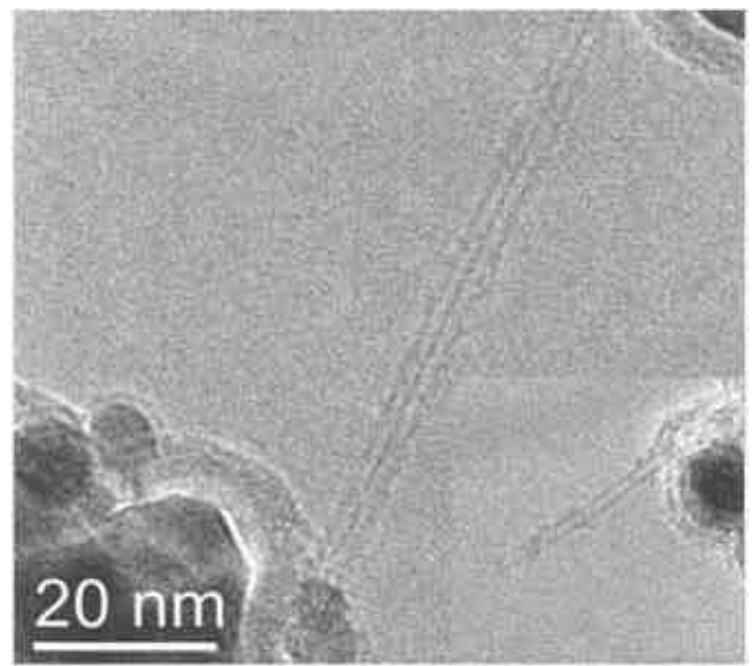

Figure 5. TEM image of SWNTs found in the outlet regions obtained by the pyrolysis of ferrocene-waterethylene-thiophene mixtures (procedure i). 


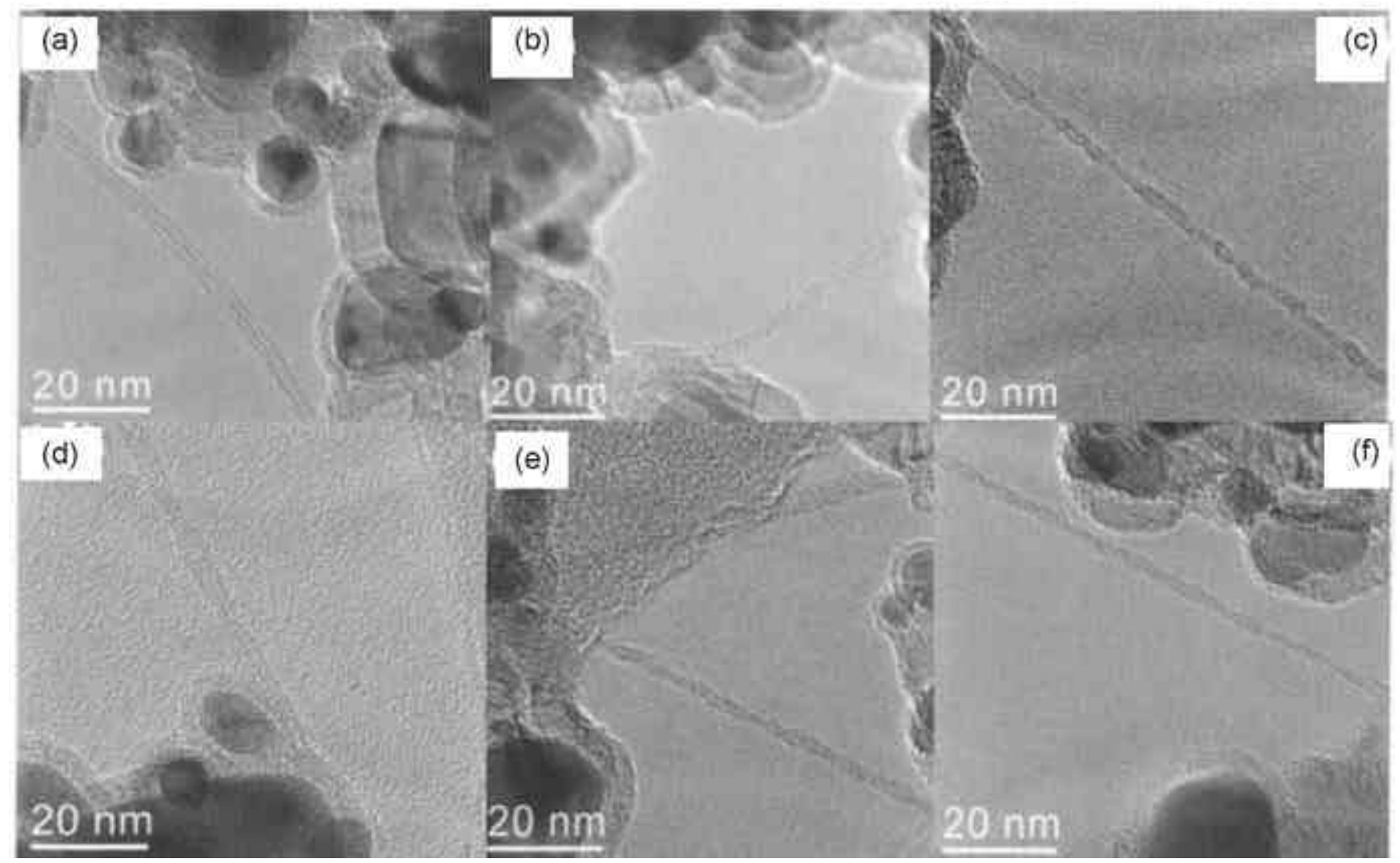

Figure 6. TEM images of SWNTs found in the outlet regions obtained by the pyrolysis of ferrocene-wateracetylene-thiophene mixtures (procedure i, using acetylene instead of ethylene).

the metal is present as nanoparticles on the silica substrate. TEM images of the Y-junctions obtained by the pyrolysis of thiophene over the $\mathrm{Ni} / \mathrm{SiO}_{2}$ catalyst are as shown in figures $3 \mathrm{a}-\mathrm{c}$. The nanotube junctions obtained by this method are as good as those obtained by the pyrolysis of metallocene-thiophene mixtures. ${ }^{3}$ The amorphous carbon material associated with the nanotubes by this procedure was, however, negligible. Furthermore, the Y-junction CNTs had a smaller diameter. Thus the outer diameters of the nanotubes shown in figures $3 \mathrm{a}-\mathrm{c}$, are 60,50 and $40 \mathrm{~nm}$ respectively, the inner diameters being 30,16 and $12 \mathrm{~nm}$ respectively. The number of graphitic layers is rather large going up to 50 layers. Multiple junction features occur commonly as can be seen in figure 3a. Long and straight junctions, several nanometres in length, are also observed.

We have also found that the presence of water vapour has a profound effect on the nature of the nanotubes obtained by the pyrolysis procedures. Accordingly, the products collected from the pyrolysis of ferrocene-water-ethylene-thiophene mixtures by procedure (i) show distinct differences in the inlet and outlet regions. The inlet regions show the presence of Y-junction MWNTs, whereas the outlet regions contain considerable quantities of SWNTs. Shown in figure $4 \mathrm{a}$ is a TEM image of the Y-junction MWNT obtained by the pyrolysis of an ethylenethiophene mixture. The corresponding high-resolution electron microscope (HREM) image is shown in figure $4 \mathrm{~b}$. The diameter of the nanotube is $\sim 25 \mathrm{~nm}$ with the number of graphitic layers being 10-15. The HREM image reveals the presence of the metal catalyst at and near the junction regions. In contrast to the inlet region, the outlet region contained copious quantities of SWNTs. Isolated SWNTs were present besides smaller bundles. We show the TEM images of SWNTs thus obtained in figure 5. In figures $6 \mathrm{a}-\mathrm{f}$, we show the TEM images of SWNTs obtained at the outlet regions when acetylene-thiophene mixture was used in pyrolysis.

In contrast to procedure (i), pyrolysis of ferrocene-thiophene mixtures in the absence of water vapour by procedure (ii), showed the presence of MWNTs with kinks and junctions. In figure $7 \mathrm{a}$, we show the HREM image of a MWNT obtained at the inlet, pos- 

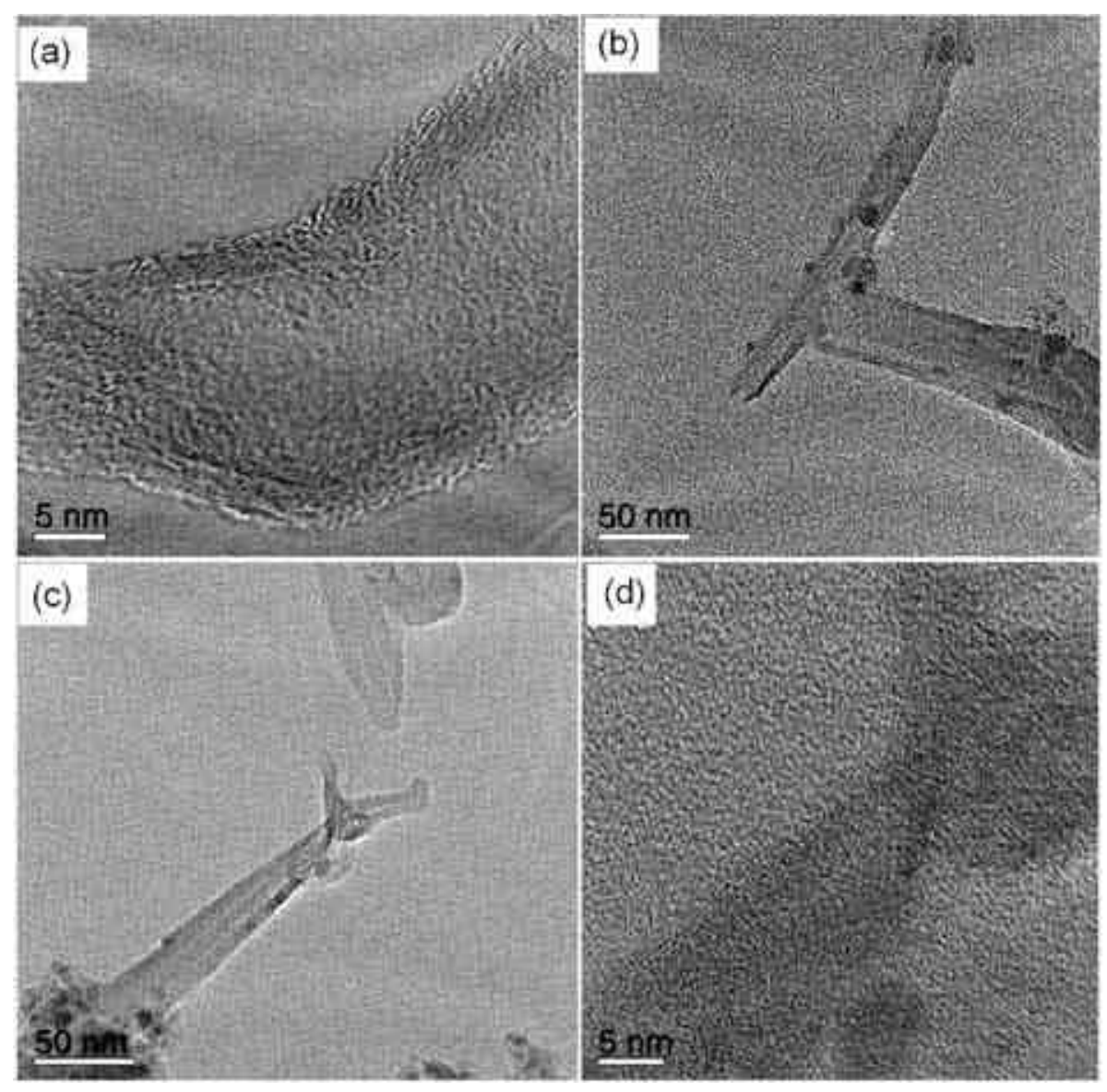

Figure 7. HREM images of MWNTs obtained by the pyrolysis of ferrocene-thiophene mixtures (procedure ii): (a) image of MWNT with a bend or a kink, (b) and (c) TEM images of T-junction and Y- junction nanotubes, (d) HREM image of the Y-junction CNT shown in (c).

sessing only $6-10$ graphitic layers. The diameter of the nanotubes in this region was around $15-25 \mathrm{~nm}$. In the outlet region, MWNTs with T- and Y-junctions were found as revealed by the TEM images shown in figures $7 b$ and $c$. An examination of the HREM image shown in figure $7 \mathrm{~d}$ reveals that the nanotube has only 6-10 graphitic layers, unlike those found in earlier preparations where the number of graphitic layers of the junction nanotubes was rather large.

\section{Conclusions}

Pyrolysis of thiophene over $\mathrm{SiO}_{2}$-supported nickel catalyst higher yields good quality Y-junction carbon nanotubes, which have much smaller diameters than those obtained by the pyrolysis of thiophene-organometallic precursors. This method may be useful to tune the diameter of the junction nanotubes suitably by varying the proportion of the nickel catalyst supported over silica. Pyrolysis of hydrocarbonorganometallic mixtures in the presence of water vapour yields SWNTs, besides MWNTS with junctions. The junction nanotubes so obtained have a reduced number of graphitic layers. The presence of T-junction nanotubes, along with Y-junction nanotubes, is significant, since they have not been observed by this method earlier.

\section{References}

1. Rao C N R and Govindaraj A 2005 Nanotubes and nanowires (London: R. Soc. Chem.)

2. Rao C N R and Govindaraj A 2002 Acc. Chem. Res. 35 998

3. Satishkumar B C, Thomas P J, Govindaraj A and Rao C N R 2000 Appl. Phys. Lett. 772530 
4. Deepak F L, John N S, Govindaraj A, Kulkarni G U and Rao C N R 2005 Chem. Phys. Lett. 411468

5. Kang Z, Wang E, Gao L, Lian S, Jiang M, Hu C and Xu L 2003 J. Am. Chem. Soc. 12513652
6. Hata K, Futaba D N, Mizuno K, Namai T, Yumura M and Iijima S 2004 Science 3061362

7. Min Y-S, Bae E J, Oh B S, Kang D and Park W 2005 J. Am. Chem. Soc. 12712498 